\title{
Hormone excretion patterns in anovulatory infertility
}

\author{
JOHN NEWTON \\ M.B., B.S., M.R.C.O.G. \\ Department of Obstetrics and Gynaecology, \\ King's College Hospital, London, S.E.5
}

BEFORE embarking upon a discussion of anovulatory infertility, it is necessary to define a physiologically normal menstrual cycle and to review our present knowledge of the hormonal changes that occur. In humans a 'normal' cycle has a mean length of 28.32 days \pm 0.6 days ( $\mathrm{SD}=5.41$ days), ovulation occurs and there must be normal corpus luteum function.

Recent reviews of the normal changes in the menstrual cycle-Van de Wiele et al. (1970); Ross et al. (1970) and Henzl \& Segre (1970)—all indicate a premenstrual rise in luteinizing hormone (LH) and follicle-stimulating hormone (FSH). For this reason it is perhaps best to consider these hormonal changes in relation to the regression of the corpus luteum at about day 23.

Figure 1 shows these changes starting 5 days before menstruation-here the plasma progesterone level is falling together with $17 \alpha$-hydroxyprogesterone. Plasma FSH and $\mathrm{LH}$ rise and this rise continues for the first 3-4 days of the cycle. This appears to initiate ripening of the Graafian follicle chosen for ovulation and this ripening follicle produces increasing amounts of oestradiol-17 $\beta$. Once a critical level of oestradiol is reached then the pituitary releases a surge of $\mathbf{L H}$ and FSH; ovulation follows about $30 \mathrm{hr}$ after this surge. Following ovulation the plasma progesterone increases rapidly as the corpus luteum is formed; $17 \alpha$-hydroxyprogesterone being a precursor on the biosynthetic pathway shows a peak prior to progesterone and coincident with $\mathrm{LH}$ and FSH.

Figure 2 shows a composite diagram of urinary hormone levels, also taken from regression of the corpus luteum and here the LH and FSH patterns mimic those of the plasma, as do urinary pregnanediol and pregnanetriol mimic those of plasma progesterone and $17 \alpha$-hydroxyprogesterone. The urinary classical oestrogens, oestradiol, oestrone and oestriol show the characteristic biphasic curve described by Brown (1955a), and here the luteal maximum is more marked for oestriol than for the other two oestrogens.

\section{Methodology}

In the clinical conditions to be described the urinary classical oestrogens have been measured by the method of Brown (1955b), urinary total oestrogens by the method of Brown et al. (1968) and

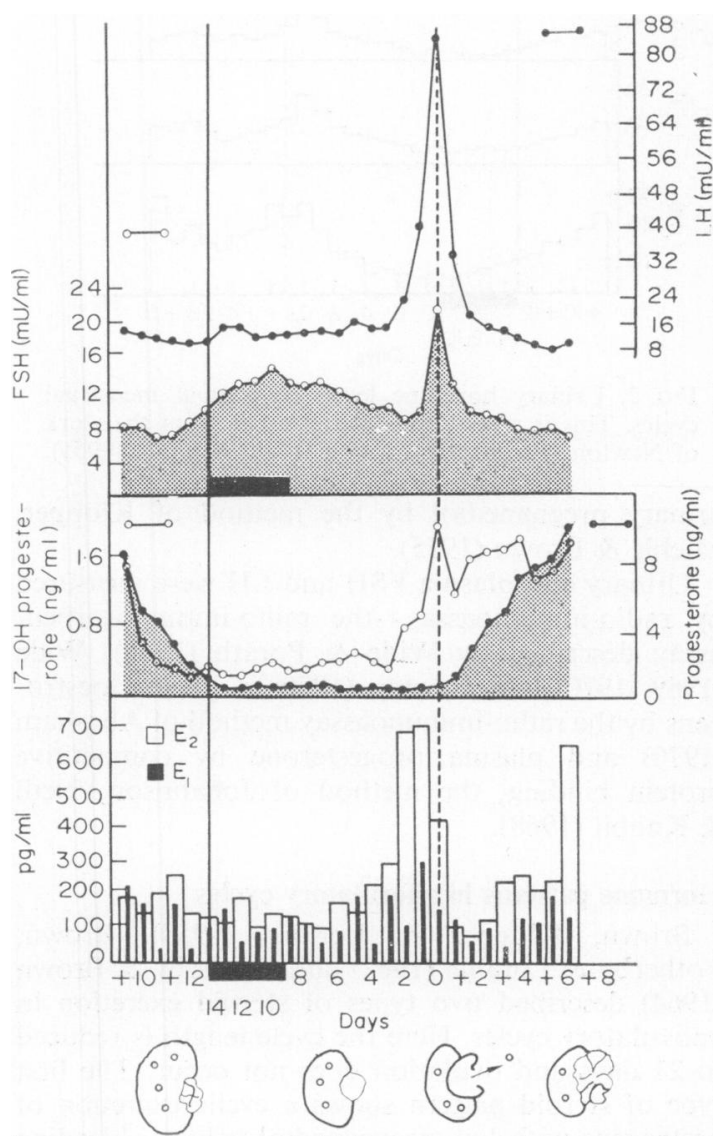

FIG. 1. Plasma hormone levels in normal menstrual cycles. This is a composite graph taken from the work of Ross et al. (1970), Van de Weile et al. (1970), Wide (1969) and Newton (1971). 


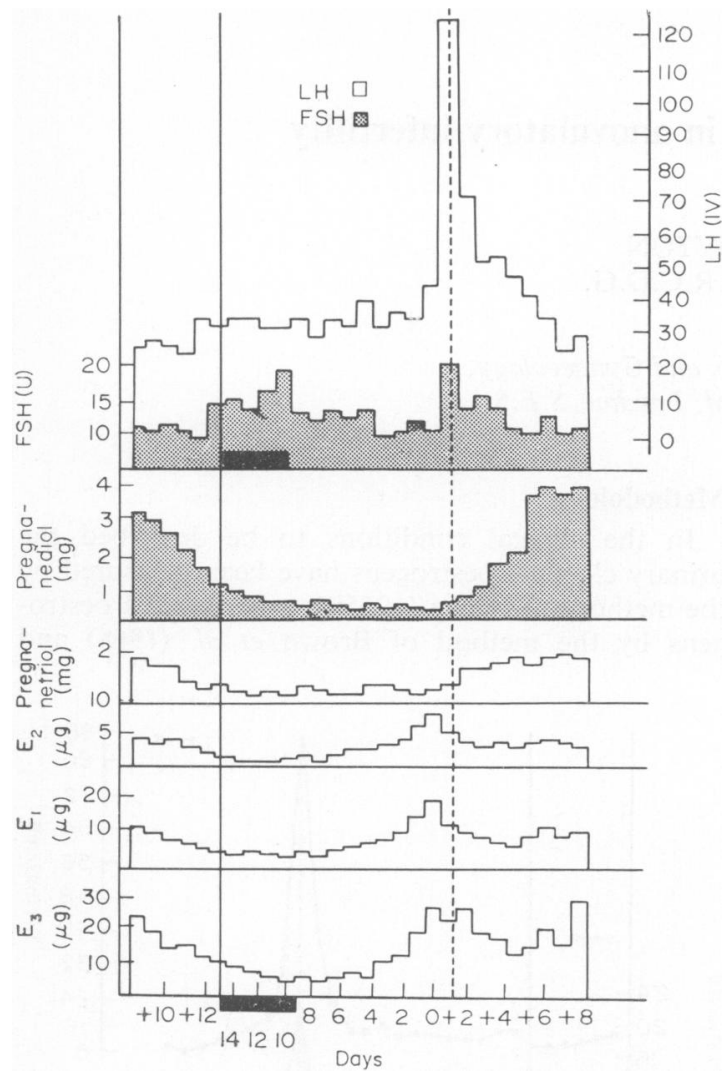

FIG. 2. Urinary hormone levels in normal menstrual cycles. This is a composite graph taken from the work of Newton (1970b), Brown (1955) and Klopper (1955).

urinary pregnanediol by the method of Klopper, Michie \& Brown (1955).

Urinary and plasma FSH and LH were measured by radio-immunoassay-the radio-immunosorbent assay described by Wide \& Porath (1966), Wide $(1969,1970)$ and Newton (1970a); plasma oestrogens by the radio-immunoassay method of Abraham (1970) and plasma progesterone by competitive protein binding, the method of Johannson, Neill \& Knobil (1968).

\section{Hormone patterns in anovulatory cycles}

Brown, Klopper \& Loraine (1958), Brown, Fotherby \& Loraine (1962) and Fotherby \& Brown (1964) described two types of steroid excretion in anovulatory cycles. Here the cycle length is reduced to 21 days and ovulation does not occur. The first type of steroid pattern shows a cyclic excretion of oestrogens with low pregnanediol values; bleeding occurs as the oestrogen levels fall.

The second pattern seen is a static excretion of oestrogens of low level. Figure 3 shows this type of

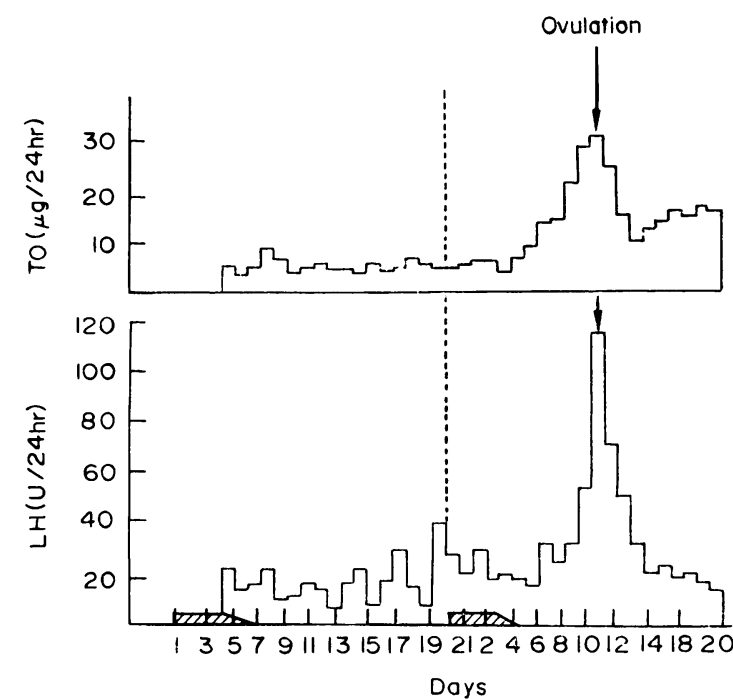

Fig. 3. Anovulatory cycle-urinary LH and total oestrogens (TO).

pattern with a 21-day cycle, low total urinary oestrogens, below $10 \mu \mathrm{g} / 24 \mathrm{hr}$, and low levels of urinary LH. There is absence of the typical biphasiê oestrogen pattern and the mid-cycle LH peak. This cycle shown in Fig. 3 is followed by a normax ovulatory cycle showing the characteristic changes:

\section{Hormone excretion in secondary amenorrhoea}

Basal excretion patterns for urinary total oestrogens and LH have been studied in 106 cases of secondary amenorrhoea. To obtain a mean basal level patients were admitted to hospital and continuous 24-hr urine samples were collected for a minimum of 6 days.

Figure 4 shows the distribution of these patients in relation to increments of $\mathrm{LH}$. The graph shows a biphasic pattern with two peaks, one at $50 \mathrm{U} / 24 \mathrm{hr}$, the other, smaller peak at $110 \mathrm{U} / 24 \mathrm{hr}$. The majority,

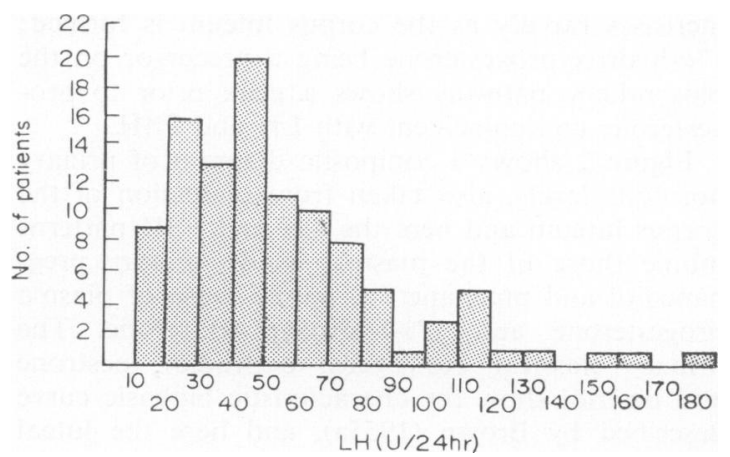

Fig. 4. LH levels in 106 patients with secondary amenorrhoea. 
fifty-eight patients, had a mean LH level below $50 \mathrm{U} / 24 \mathrm{hr}$. This shows a higher mean value than for normal menstruating women of $38 \mathrm{U} / 24 \mathrm{hr}$ (Newton, 1970b).

Figure 5 shows the same group of women grouped according to their mean basal excretion of urinary total oestrogens. Here the majority, eighty-three patients, had values below $15 \mu \mathrm{g} / 24 \mathrm{hr}$.

Figure 6 shows this same group with the LH values plotted against the total oestrogen excretion.

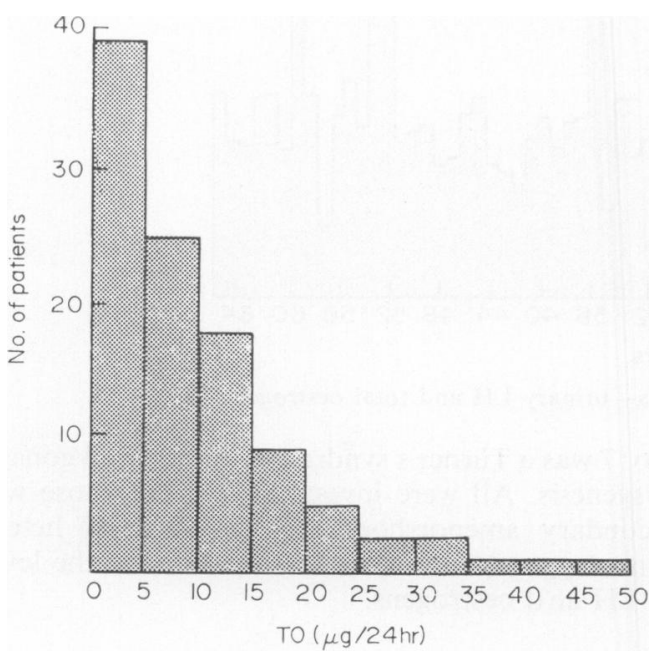

FIG. 5. Total urinary oestrogen (TO) in 106 patients with secondary amenorrhoea.

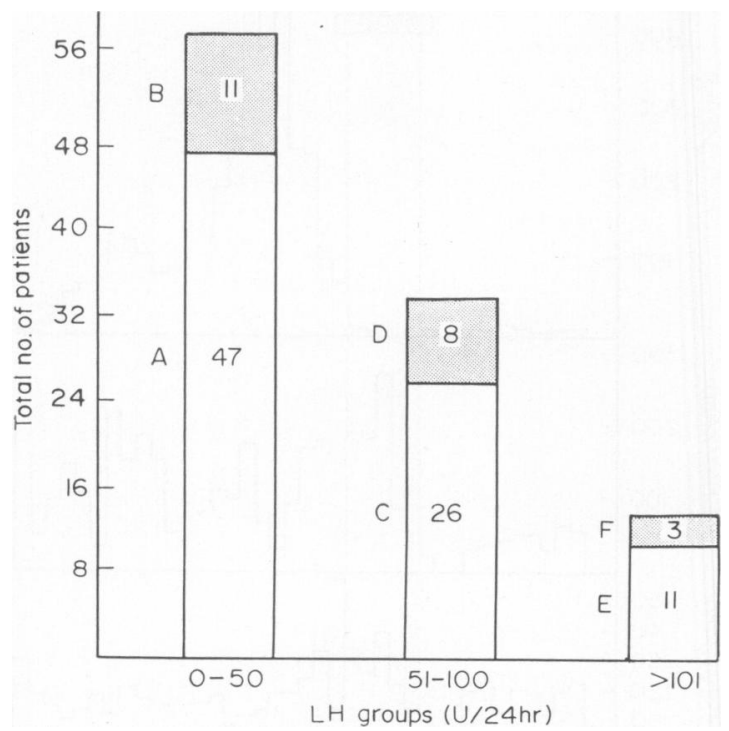

FIG. 6. Secondary amenorrhoea LH and oestrogen groups (106 patients). Open columns, oestrogen $<15 \mu \mathrm{g} / 24 \mathrm{hr}$; stippled columns, oestrogen $>15$ $\mu \mathrm{g} / 24 \mathrm{hr}$.
The groups, A and B, excreted less than $50 \mathrm{U} / 24 \mathrm{hr}$ of LH. Group B, eleven patients, excreted more than $15 \mu \mathrm{g} / 24 \mathrm{hr}$ of oestrogen; this group is liable to hyperstimulation with sequential gonadotrophic induction of ovulation and clomiphene should be used initially. Group A, forty-seven patients, excreted less than $15 \mu \mathrm{g}$ of oestrogen, did not respond to clomiphene and sequential gonadotrophin therapy can be used without risk of overstimulation.

Groups C and D excreted 50-100 U/l of LH. Here Group D excreted more than $15 \mu \mathrm{g}$ of oestrogen. All these patients had spontaneous return of menstruation within 6 months of investigation and needed no treatment. Group C, twenty-six patients, less than $15 \mu \mathrm{g}$ of oestrogen, were a mixed group and some responded to clomiphene, others to sequential gonadotrophin therapy.

Groups $\mathrm{E}$ and $\mathrm{F}$-here $\mathrm{LH}$ levels were high, greater than $100 \mathrm{U} / 24 \mathrm{hr}$ and in Group E, three patients excreting more than $15 \mu \mathrm{g}$ of oestrogen, were found to have polycystic ovaries on laparoscopy. Group F, high LH and low oestrogen, less than $15 \mu \mathrm{g} / 24 \mathrm{hr}$ - eleven patients, all had smaller than normal ovaries when examined at laparoscopy.

To obtain a reliable estimate of mean basal excretion, we have used five or six consecutive 24-hr urine collections; to evaluate the pattern over larger periods of time, nineteen of these patients collected continuous samples from 14 to 64 days. These changes are reviewed in more detail elsewhere (Newton, 1971). Figure 7 shows an example of a cyclical pattern with peaks occurring every 3-5 days and only on one occasion, the midpoint of the sample collection, was there an oestrogenic response.

Table 1 shows the precipitating cause of the secondary amenorrhoea and here thirty-two patients $(29 \%)$ had psychiatric causes. Two were schizoid, four had depression, twenty-five had a precipitating episode of stress, usually due to changing a job, emotional upsets or to the start of student training, and one patient had anorexia nervosa. Thirty-two patients $(29 \%)$ had preceding oligomenorrhoea. Eleven patients had the self-starvation syndrome, eight post-pill amenorrhoea-all these had been on high dose combined oral contraception and all had preceding oligomenorrhoea before the start of oral contraception. Eight suffered from obesity (all being more than $10 \mathrm{~kg}$ over their computed weight for age and height). Two had the Stein-Leventhal syndrome, and there were nine others including one with a pituitary adenoma, one with diabetes mellitus and in one no precipitating cause could be found.

Following assessment of their basal endocrine state and routine clinical investigation as described by Newton (1971), these patients were then given a pituitary reserve test (PRT) using oral clomiphene 

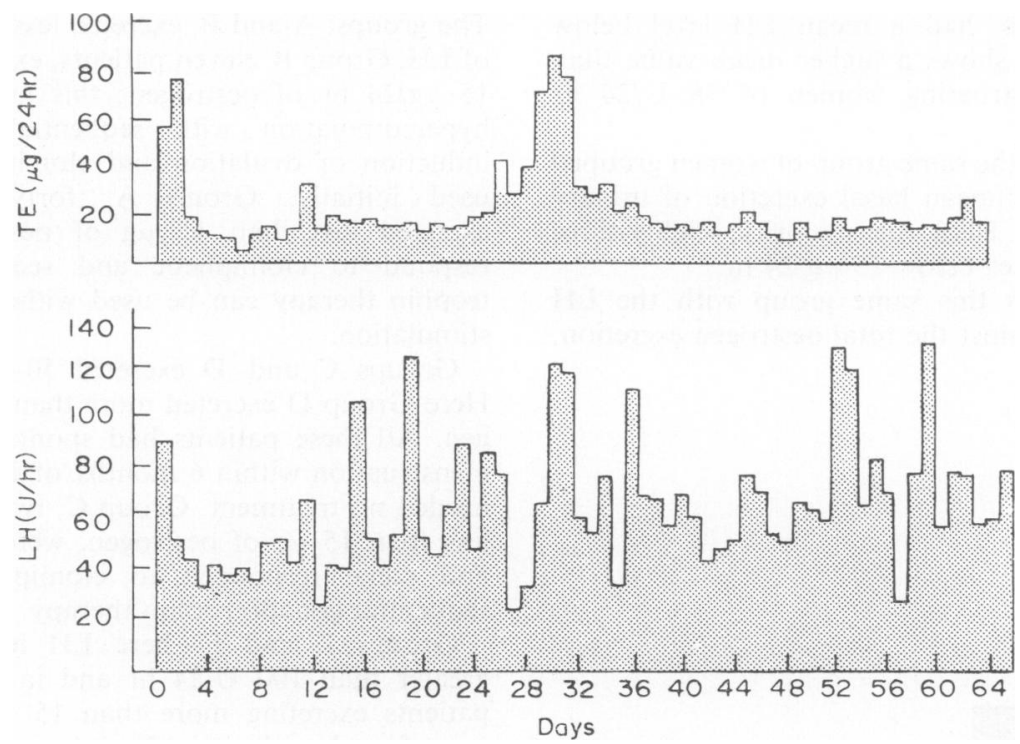

FIG. 7. Excretion pattern in secondary amenorrhoea-urinary LH and total oestrogen (TE).

TABle 1. Precipitating cause of secondary amenorrhoea

\begin{tabular}{lcc}
\hline & Main & Secondary \\
\hline Stress & $25^{*}$ & 0 \\
Depression & 4 & 0 \\
Psychiatric & & \\
$\quad$ Psychosexual & 0 & 1 \\
Schizoid & 2 & 0 \\
Anorexia nervosa & 1 & 0 \\
$\quad$ Total & 32 & 1 \\
Oligomenorrhoea & $32 \dagger$ & 25 \\
Self starvation & $11^{*}$ & 3 \\
Post-pill & 8 & 1 \\
Post-partum & $8 \ddagger$ & 0 \\
Obesity & $8 \dagger \ddagger$ & 0 \\
Stein-Leventhal & 2 & 0 \\
Hirsute & 0 & 5 \\
Others & 9 & 4 \\
Total & 110 & 40 \\
$\quad$ Corrected total & 106 & 40 \\
\hline
\end{tabular}

$$
\begin{aligned}
& *=1 \text {,starve }+ \text { stress. } \\
& \dagger=2 \text {,oligomenorrhoea }+ \text { obesity. } \\
& \ddagger=1 \text {,obesity }+ \text { post-partum. }
\end{aligned}
$$

to see if the pituitary had the capacity to release gonadotrophins. This test has previously been reported (Newton, 1970c). Figure 8 shows an example with a patient given $200 \mathrm{mg}$ of clomiphene. Here, LH and FSH are seen during treatment to rise to more than twice the basal level and oestrogen excretion reaches its maximum after completion of clomiphene.

\section{Hormone excretion in primary amenorrhoea}

Figure 9 shows LH plotted against oestrogens in seven patients with primary amenorrhoea. Patient
No. 7 was a Turner's syndrome, the rest had gonadal dysgenesis. All were investigated as for those with secondary amenorrhoea. This is a small heterogeneous group and there is no pattern to the levels of LH and oestrogens.

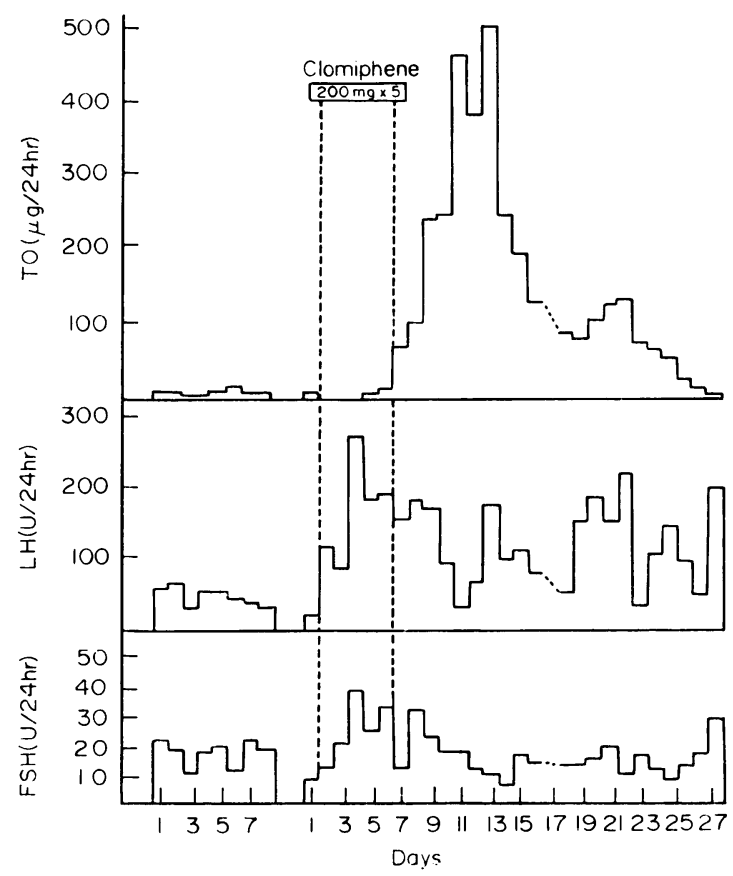

FIG. 8. Pituitary reserve test (PRT) using clomiphene. 


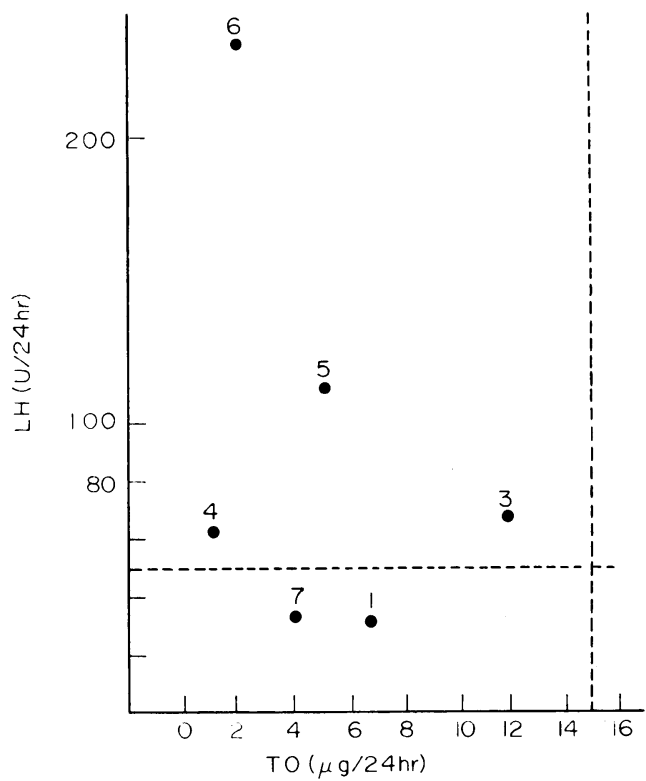

Fig. 9. Primary amenorrhoea.

\section{References}

Aвrahams, G.E. (1969) Solid-phase radio-immunoassay of estradiol 17ß. Journal of Clinical Endocrinology, 29, 866.

Brown, J.B. (1955a) Urinary excretions of oestrogens during the menstrual cycle. Lancet, i, 320.

Brown, J.B. (1955b) A chemical method for the determination of oestriol, oestrone and oestradiol in human urine. Biochemical Journal, 60, 185.

Brown, J.B., Klopper, A. \& Loraine, J.A. (1958) The urinary excretion of oestrogens, pregnanediol and gonadotrophins during the menstrual cycle. Journal of Endocrinology, 17, 401 .

Brown, J.B., Fotherby, K. \& Loraine, J.A. (1962) The effect of Norethisterone and its acetate on ovarian and pituitary function during the menstrual cycle. Journal of Endocrinology, 25, 331.
Brown, J.B., Macleod, S.C., Macnaughton, C., Smith, M.A. \& SMYTH, B. (1968) A rapid method for estimating oestrogens in urine using a semi-automatic extractor. Journal of Endocrinology, 42, 5.

Fotherby, K. \& Brown, J.B. (1964) Pregnanetriol, pregnanediol and oestrogen excretion during anovulatory menstrual cycles and in a premenopausal adrenalectomized woman. Journal of Endrocrinology, 29, 55.

Henzel, M.R. \& Segre, E.J. (1970) Physiology of the human menstrual cycle and early pregnancy. Contraception, $1,315$.

Johansson, E.D.B., NeILl, J.D. \& KNobiL, E. (1968) Periovulatory progesterone concentration in the peripheral plasma of the Rhesus monkey with a methodological note on the detection of ovulation. Endocrinology, 82, 143.

Klopper, A., Michie, E.A. \& Brown, J.B. (1955) A method for the determination of urinary pregnanediol. Journal of Endocrinology, 12, 209.

Newton, J.R. (1970a) In: Workshop on Radio-immunoassay Methods (Ed. by Kirkham \& Hunter). Livingstone, London.

NEWTON, J.R. (1970b) Radio-immunosorbent assay for LH and FSH, its application to gynaecology and the study of the site of action of clomiphene. Journal of Fertility and Sterility, 22, 187.

Newton, J.R. (1970c) Ciba Symposium, Research Methods in Endocrinology (Ed. by Strong). Livingstone, London.

Newton, J.R. (1971) Journal of Obstetrics and Gynaecology of the British Commonwealth, (in press).

Ross, G.T., Cargille, C.M., Lipsett, M.B., Rayford, P.L., Marshall, J.R., Strott, A.C. \& Rodbard, D. (1970) Pituitary and gonadal hormones in women during spontaneous and induced ovulatory cycles. Recent Progress in Hormone Research, 26, 1.

Van de Wiele, R.L., Bogumiel, J., Dyrenfurth, I., Ferin, M., Jewelewicz, R., Warren, M., Rizkallah, T. \& MikhaiL, G. (1970) Mechanisms regulating the menstrual cycle in women. Recent Progress in Hormone Research, 26, 63.

Wide, L. \& PORATH, J. (1966) Radio-immunoassay of proteins with the use of sephadex-coupled antibodies. Biochemica Biophysica Acta, 130, 257.

WIDE, L. (1969) Radio-immunoassays employing immunosorbents. Acta Endocrinologica, Suppl. 142, 207.

WIDE, L. (1970) In: Workshop on Radio-immunoassay Methods (Ed. by Kirkham \& Hunter). Livingstone, London. 